\title{
Design of Self-practice Listening and Supplementary Vocabulary Exercises for a TOEFL-ITP Preparation Course in Vietnam
}

\author{
Duy Ngoc Pham (Corresponding author) \\ Department of International Training, Thai Nguyen University of Technology, Viet Nam \\ Tel: 84-984-041-004Ｅ-mail: duypn279@gmail.com
}

\begin{abstract}
Thu Thi Xuan Nguyen
Department of International Training, Thai Nguyen University of Technology, Viet Nam

Tel: 84-977-300-711Ｅ-mail: xuanthutn@ gmail.com
\end{abstract}

Received: July 26, 2017 Accepted: September 13, 2017 Published: September 15, 2017

doi:10.5296/ijele.v5i2.11869 URL: https://doi.org/10.5296/ijele.v5i2.11869

\begin{abstract}
The amount of information to be accumulated at university has been increasing in recent years, so students nowadays are moving towards using computers in the learning process. Application of Information and Communication Technology (ICT), particularly educational software, to facilitate the learning and teaching process has become a more and more popular trend among teachers. In Thai Nguyen University of Technology (TNUT), Vietnam, a multi-disciplinary virtual learning environment (http://e-learning.tnut.edu.vn) has been established on the MOODLE platform. The aim of this paper is to introduce the design of self-practice listening and vocabulary exercises for the TOEFL-ITP preparation course by integrating the exercises designed with the Hot Potatoes and Quizlet into TNUT's institutional e-learning system. First, the advantages of the e-learning system are discussed. Second, the tools and materials necessary for the design are described. Finally, a suggestion on integrating the listening and vocabulary exercises designed by the Hot Potatoes software and Quizlet into the available e-learning system is introduced.
\end{abstract}

Keywords: E-learning, hot potatoes, TOEFL-ITP listening, vocabulary 


\section{Introduction}

EFL material producer and curriculum developers have shown interest in including computer-based and electronic materials in their syllabi since technology has completely changed the ways materials are made and use in EFL classrooms. Reinders and White (2010) contend that Computer Aided Language Learning (CALL) materials can include "tasks, websites, software, courseware, online courses and virtual environments" (p. 59). Generally, using electronic materials will supply EFL practitioners with various kinds of affordances, including interactivity, easiness of access and storage, authenticity, collaboration, instant feedback, control and empowerment, and facilitation of learning (Kervin \& Derewianka,2011; Motteram, 2011; Tomlinson, 2012). Perhaps, the most significant value of using electronic materials is that they provide teachers and students a myriad of choices and introduce flexibility to both teaching and learning (Tomlinson, 2012). More essentially, what makes electronic materials more beneficial and popular in language teaching is that they are more accessible than materials used in traditional language teaching courses.

This article partially emerges from the challenges that teaching TOEFL preparation courses poses to language teachers at TNUT. Among these challenges, listening comprehension is considered one of the most challenging tasks for TOEFL test-takers. Moreover, listening is also one of the main areas where students fail to obtain high scores in the TOEFL test at TNUT.

In TNUT, first year students in the Advanced Programs are given ten credits to learn English and they are supposed to take the TOEFL test at the end of the course. Since 2015, the students are required to get TOEFL-ITP 500 certificate as one of the preliminary criteria for graduation. TOEFL ITP tests are paper-based and use academic content to assess the English-language proficiency of non-native English speakers. In order to achieve TOEFL-ITP 500 or more, the students need to own a sufficiently good listening skill. Listening comprehension is one of the most difficult parts to get high scores in TOEFL. There are many possible causes to this. One of the problems that persist is their limited vocabulary. Therefore, a set of supplementary exercises is designed through Quizlet to assist the learners with listening to the lectures full of words used in lectures. TNUT has had the e-learning system implemented comprehensively for all the disciplines. This leads the author to thinking of making the most use of the available e-learning platform to design listening exercises to help students prepare better for the TOEFL.

\section{The E-learning System}

According to The American Society for Training and Development, e-learning is a large set of applications and processes including web-based learning, computer-based learning, virtual classrooms, and digital contents. How e-learning is defined depends on how it is used, but essentially, it is related to electronic ways of communication, education, and training.

Essentially, Learning Management System (LMS) is an application intended to manage, document, find and report training programs, classroom and online events, e-learning 
programs, and training content. It is also popular as a web-based technology, which is used to plan, implement and evaluate a specific learning process. The system controls the training and educational records and distribute them as well. The benefits of LMS range from training management and educational records maintaining to course distribution over the Internet with features for online collaboration.

The MOODLE learning platform allows educators to create online courses. Since it was established in 1999, the MOODLE community has grown so much. MOODLE is the software designed to help educators in creating easily high-grade online courses. These systems are possibly called Learning Management Systems or Virtual Learning Environments.

At TNUT, the e-learning system, established since the academic year 2013-2014, has enabled the lecturers to create online exercises and facilitate the students' learning process, particularly the English language learning process. The system is available, but how to make the most use of this available system is another story. It seems that the e-learning system has just been used as an electronic tool to post the lectures under DOC or PowerPoint format. The author has seen an opportunity to facilitate the students' learning process hidden in the e-learning system.

\section{Tools and Procedures}

\subsection{The Materials}

As mentioned earlier, the authors wish to design a set of self-practice exercise to supplement the in-class learning process. These exercises would increase the practice frequency of the students for the lessons they learn in class. Therefore, Longman Preparation Course for the TOEFL Test and Longman Introductory Course for the TOEFL Test by Deborah Phillips were chosen to design self-practice exercises and tests. Furthermore, a supplementary set of vocabulary exercises would also be designed to help the students become familiar with the words appearing in TOEFL-ITP exam. The material chosen for the design of vocabulary exercises is 400 Must-Have words for the TOEFL by Lynn Stafford et al.

\subsection{The Hot Potatoes Software}

The Hot Potatoes software is comprised of six applications designed by the Research and Development team at the University of Victoria Humanities Computing and Media Center. Through the Hot Potatoes software, web interactive excises and tests can be made only by inputting data, allocating settings and publishing them. Though Hot Potatoes is not part of MOODLE, it is possible for the exercises created in Hot Potatoes to be imported and integrated in MOODLE.

The six componential programs in the software can be used in creating interactive exercises and are especially suitable for foreign language learning.

The exercises are created using six programs: 
1. JQuiz- a quiz with a multiple choice of answers

2. Jcloze - filling in missing word/phrase

3. Jmatch- exercises related to matching the correct object with the correct word/ phrase by dragging and dropping items.

\section{Jcross- crossword puzzles}

5. Jmix - putting the words/phrases in the word or phrases in the correct order using correct order

6. Jmasher program- making it possible to combine various exercises and materials in exercises and courses based on topics.

The exercises designed with Hot Potatoes can be saved in a web format and then imported into the e-learning system with SCORM exercise or practice tests.

\subsection{Quizlet}

"The internet site Quizlet allows users to make and study flashcard sets using a variety of game-like learning tools. Quizlet is one of the most widely used flashcard websites and has more than one million registered users and eighty million visitors, and is a repository for over thirty million user-generated study sets" (Quizlet, 2014).

Nation (2001) contends that "Using flashcards is a time-honored, effective, and efficient vocabulary learning strategy". The arrival of information and communication technology (ICT) over the past few decades has enabled EFL learners to maximize vocabulary learning through the employment of web-based flashcard programs. The advantages of web-based flashcard programs may even outweigh those of paper-based ones. These programs may be useful in helping enlarge students' vocabulary size, track students' learning progress over time and boost motivation by introducing new words strategically, introducing vocabulary with multimedia, and enabling learners to study anytime provided that the students are accessible to the internet. (Allum, 2004; Altiner, 2011; Hulstijn, 2001; McLean, Hogg, \& Rush, 2013; Nakata, 2011).

\subsection{Procedures}

Of all the programs included in Hot Potatoes, the researcher decided to choose JQuiz for the design of the exercises. The first 2 listening exercise sets follow the same procedure. First, the exercises were selected from the textbooks. By this time, the researcher had had all the necessary data. What he needed to do next is to input these data into the software Hot Potatoes. After the data were included in the database, the SCORM exercises were created within the software. Finally, these SCORM exercises were integrated into the institutional e-learning system of TNUT.

The set of vocabulary exercise was designed in a different way from the first two sets. First, selected topics were chosen from the 400 Must-Have words for the TOEFL by Lynn Stafford et al. Then these exercises were transferred into Quizlet online platform. After being 


\section{Ml Macrothink}

transformed into vocabulary exercises, the Quizlet files were saved in the HTML form, which will be finally integrated into the institutional e-learning system.

\section{Results and Discussions}

The courseware includes 11 TOEFL Introductory listening exercises, 32 TOEFL Preparation listening exercises, 15 practice tests and 40 Quizlet vocabulary exercises.

\subsection{Three Sets of Self-access Listening Exercises}

There are three sets of self-access listening. The first two consist of 43 multiple choice exercises designed on Hot Potatoes based on the two textbooks Longman Preparation Course for the TOEFL Test and Longman Introductory Course for the TOEFL Test. The third set is composed of 15 practice tests.

For the first two sets, these are the exercises which are used for the purpose of complementing the face-to-face TOEFL listening lessons in class. All the exercises in the two above-mentioned textbooks are computerized. This means that the students can practice these exercises at home to consolidate what they have learned in class. Since these exercises are designed on Hot Potatoes JQuiz platform, they can be used as an assessment tool to facilitate teachers' grading after being embedded into the e-learning system. Teachers can encourage the students to do the exercise by choosing the highest grading option. Moreover, it is possible for the students to reselect the answers in case of wrong answers, which help them practice the lessons better.
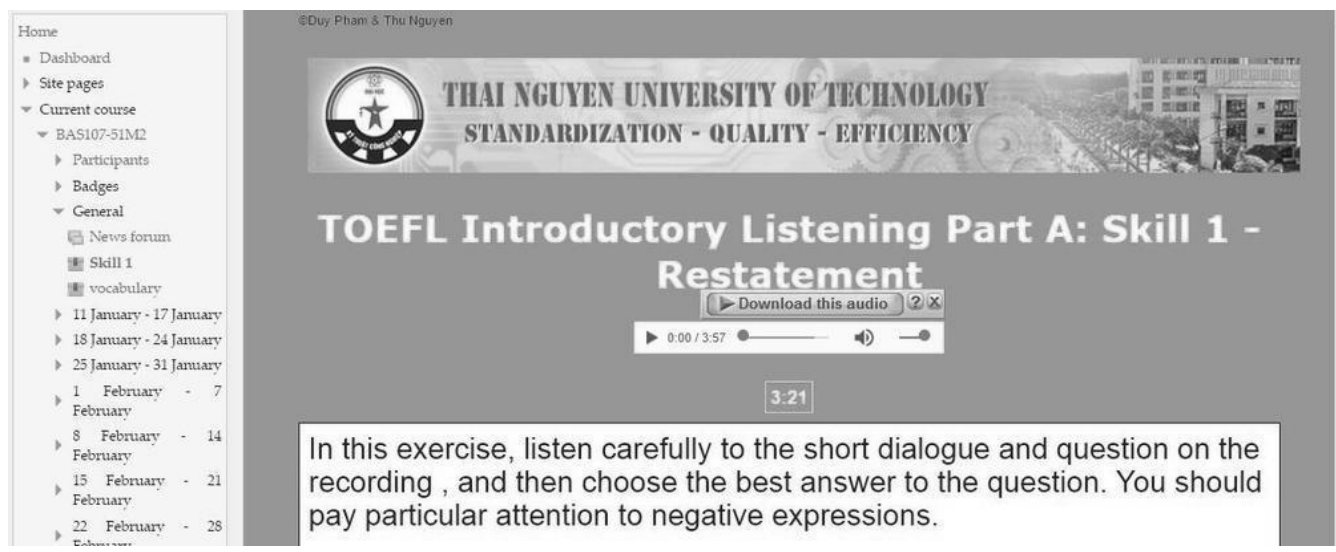

Figure 1. A TOEFL Introductory listening exercise embedded into the e-learning system 


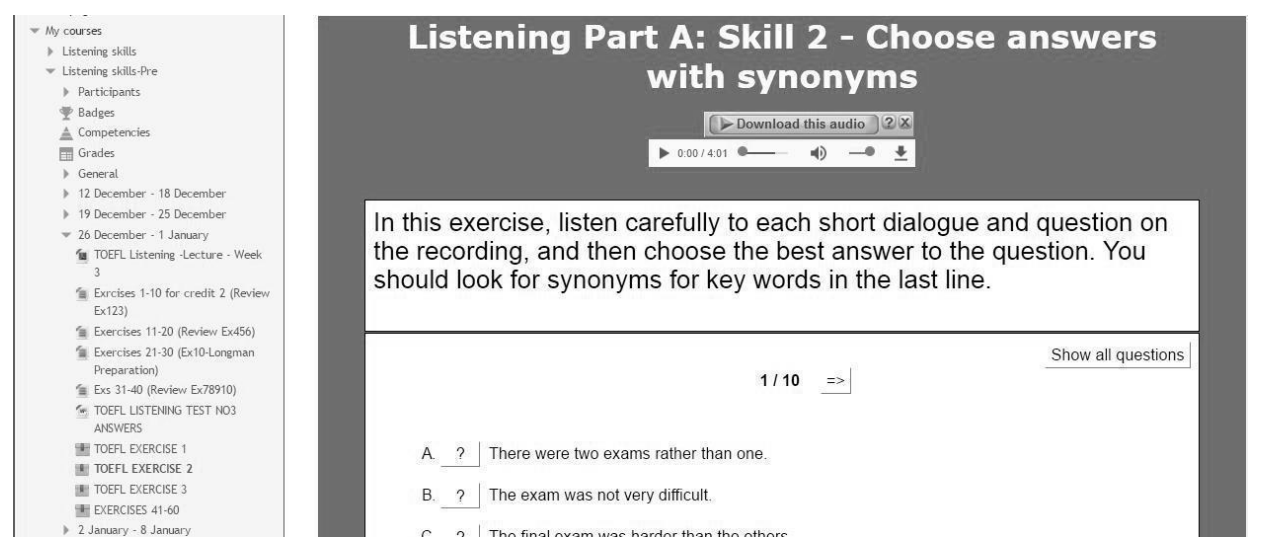

Figure 2. A TOEFL Preparation listening exercise embedded into the e-learning system

The second set includes 15 self-access listening practice tests, which are intended to serve the students' self-evaluation of their progress. These tests are selected from Cambridge Preparation for the TOEFL® Test, Fourth Edition and Longman Preparation Course for the TOEFL Test.

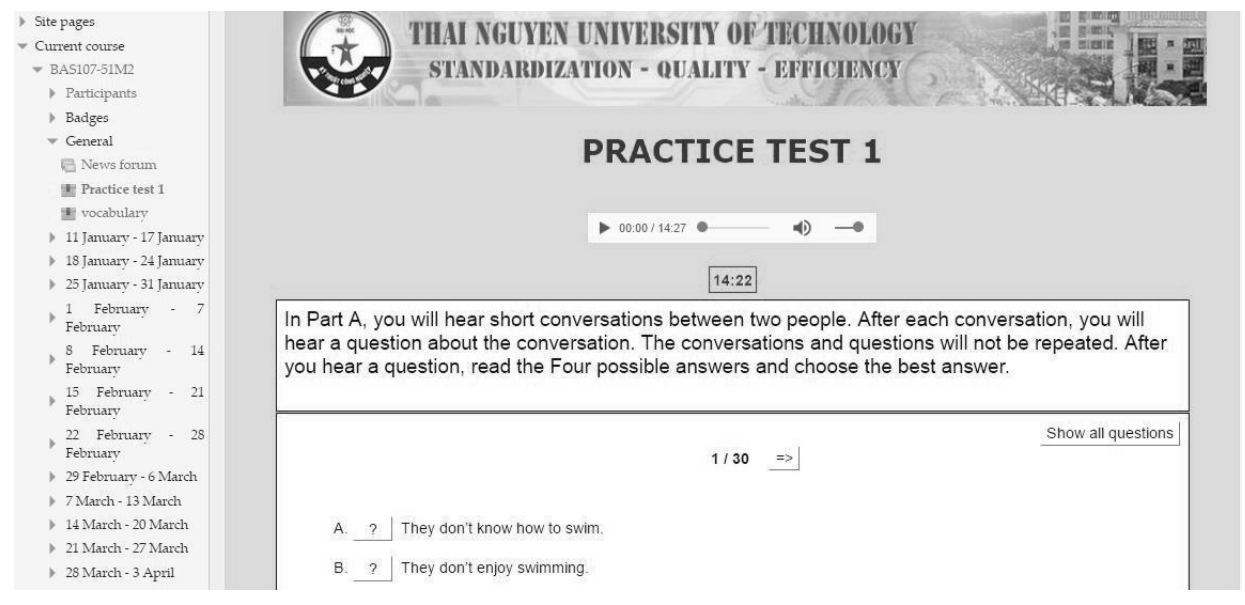

Figure 3. A TOEFL practice exercise embedded into the e-learning system

\subsection{Quizlet Vocabulary Exercises}

The third set is composed of vocabulary self-practice exercises covering the whole 40 vocabulary topics in the 400 Must-Have words for the TOEFL by Lynn Stafford et al. These topics cover most of the academic words, which frequently occur in TOEFL listening and reading. 


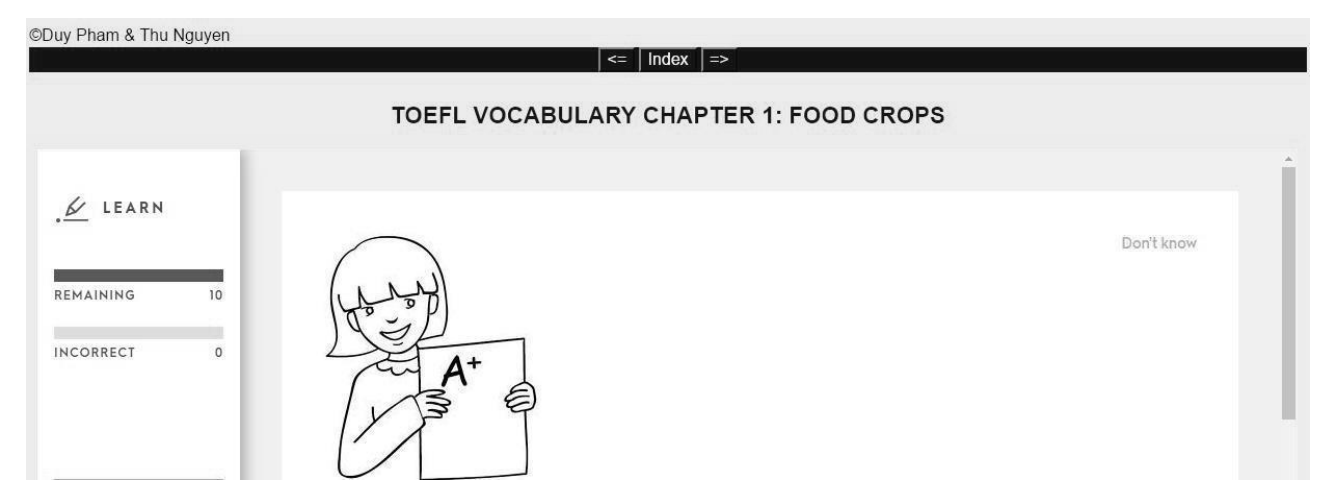

Figure 4. A Quizlet vocabulary embedded into the e-learning system

The development of the electronic content for the TOEFL preparation course is done gradually to assist the students in acquiring and strengthening vocabulary. The quizzes are checked automatically and can be re-checked since there are changes in the questions used.

The lecturer can provide the specific test begin and test end dates, as well as test duration. He can also decide how many times a quiz taker can do the same test, and if the student himself will be able to see his result of the quiz.

As the exercises have been integrated into the e-learning system, it is easier for the lecturer to supervise his students' participation in the learning process with various types of reports including objectives and interaction reports.

The exercises created with the Hot Potatoes can be imported into the institutional e-learning system under the SCORM format. The duration of each lesson or quiz is not unlimited. It is defined by the lecturer based on the complexity and size of the material. The number of repetitions of every activity can be limited. In addition, the students can study anywhere as long as they have access to a computer with internet connection; there is a learners' flexibility to participate in the discussions any time of the day; the students can work at their own place; they can accommodate to different learning styles using different activities. Moreover, it is possible for the learners to keep reviewing all the lessons with the available e-learning resources. This is a particularly important preparation for the learners for class lessons as well as a source of materials for their self-studies.

\section{Conclusion}

It can be said that teaching listening will always be a demanding task for language teachers. Nonetheless, the use of free authoring tools such as Hot Potatoes and Quizlet opens new doors to teachers as they empower themselves to create and design materials suited to their students' needs. With two sets of self-practice exercise and tests designed with the Hot Potatoes suite and one set of supplementary vocabulary exercise integrated into the e-learning 
system at TNUT, the author would like to suggest a design of self-practice listening exercises with supplementary vocabulary exercise for learners who take the TOEFL-ITP preparation course. Further studies should be conducted to evaluate the effectiveness of this application.

\section{References}

Allum, P. (2004). Evaluation of CALL: Initial vocabulary learning. ReCALL, 16(2), 488-501. https://doi.org/10.1017/S0958344004001624

Altiner, C. (2011). Integrating a computer-based flashcard program into academic vocabulary learning. Doctoral dissertation, Iowa State University, the USA. Retrieved from http://lib.dr.iastate.edu/cgi/viewcontent.cgi?article=1122\&context=etd

Dudeney, G., \& Hockly, N. (2008). How to teach English with technology. Harlow, Essex: Pearson Education. https://doi.org/10.1080/09588220701865474

Hulstijn, J. H. (2001). Intentional and incidental second language vocabulary learning: A reappraisal of elaboration, rehearsal, and automaticity. In P. Robinson (Ed.), Cognition and second language instruction (pp. 258-286). Cambridge: Cambridge University Press. https://doi.org/10.1017/CBO9781139524780.011

Frei, S., \& Gammill, A. (2007). Integrating technology into the curriculum. Huntington Beach, CA: Shell Education.

Half-Baked Software Inc. (2009). Hot Potatoes version 6. Retrieved from http://hotpot.uvic.ca/hotpot6_help.pdf

Hoven, D. (1999). A model for listening and viewing comprehension in multimedia environments. Language Learning \& Technology, 3(1), 88-103. Retrieved May 11, 2017 from http://lit.msu.edu/vol3num1/hoven/

Kervin, L., \& Derewianka, B. (2011). New technologies to support language learning. In B. Tomlinson (Eds.), Materials Development in Language Teaching (pp. 328-351). Cambridge: Cambridge University Press.

McLean, S., Hogg, N., \& Rush, T. W. (2013). Vocabulary learning through an online computerized flashcard site. The jaltcalljournal, 9(1), 79-98.

Nakata, T. (2011). Computer-assisted second language vocabulary learning in a paired-associate paradigm: A critical investigation of flashcard software. Computer Assisted Language Learning, 24, 17-38. https://doi.org/10.1080/09588221.2010520675

Nation, I.S.P. (2001). Learning vocabulary in other language. NY: Cambridge University Press. https://doi.org/10.1017/CBO9781139524759

Quizlet. (2014). About Quizlet. Quizlet. Retrieved from http://quizlet.com/mission

Reinders, H., \& White, C. (2010). The theory and practice of technology in materials development and task design. In N. Harwood (Ed.), English Language Teaching Materials: 
Theory and Practice (pp. 58-80). Cambridge: Cambridge Press University.

Solvie, P., \& Kloek, M. (2007). Using technology tools to engage students with multiple learning styles in a constructivist-learning environment. Contemporary Issues in Technology and Teacher Education, 7(2), 7-27.

\section{Copyright Disclaimer}

Copyright for this article is retained by the author(s), with first publication rights granted to the journal.

This is an open-access article distributed under the terms and conditions of the Creative Commons Attribution license (http://creativecommons.org/licenses/by/3.0/). 